\title{
Transplantation of cryopreserved human heart valves in Europe: 30 years of banking in Brussels and future perspectives
}

\author{
Ramadan Jashari $\mathbb{B}$
}

Received: 11 November 2020/Accepted: 20 January 2021/Published online: 2 February 2021

(C) The Author(s), under exclusive licence to Springer Nature B.V. part of Springer Nature 2021

\begin{abstract}
For over 30 years, our TE has processed, controlled for quality and distributed cryopreserved allograft valves for human application. We present a review of this activity and future perspectives of cardiovascular tissue banking. The donor age and medical/behavioral history are in compliance with the regulations of the EUMS. Allograft morphology and function are evaluated in a class A cleanroom. Tests for viral/bacterial infection, histological control of structure/infection/malignancy and control-rate cryopreservation are performed. A total of 7562 hearts were sent to our TE, whereas 7290 valves (pulmonary, aortic and mitral) were transplanted. The donations increased over time: 1934, 2566 and 3062 hearts were donated during the first, second and third decades (increases of 32.7 and $19.3 \%$ during the second and third decades). Likewise, there was a significant increase in transplantations with 2050, 2550 and 2690 valves implanted during the first, second and third decades (24.4 and $5.5 \%$ increase during the second and third decades). A total of 4475 pulmonary (61.4\%), 2760 aortic (37.9\%) and 55 mitral valves $(0.7 \%)$ were transplanted. Outstanding long-term results in adults and evidence of immune-related deterioration of allografts in neonates and infants were demonstrated. Decellularization was suggested as a
\end{abstract}

R. Jashari $(\square)$

European Homograft Bank (EHB), EHB, Méridien Site, Rue du Méridien 100, 1210 Brussels, Belgium e-mail: rjashari@clstjean.be solution. One hundred pulmonary and 180 aortic valves were sent for transplantation after decellularization for the ESPOIR and ARISE clinical trials and beyond. The donation and transplantation activity increased progressively. Although cryopreserved valves represent the best substitute for diseased valves, accelerated failure appears after implantation in neonates and infants. The implementation of new technologies, such as decellularization, as a standard procedure for treatment of allograft valves will offer further improvements in allograft quality and increase of durability.

Keywords Decellularization - Cardiovascular tissue banking · Cryopreservation · Heart valve allografts . Transplantation

\section{Introduction}

Pioneering work in the clinical application of human heart valves (homografts, allografts) was reported by Gordon Murray in 1956 in Toronto (Murray et al. 1956) when he implanted the first aortic valve in the descending thoracic aorta for the treatment of a diseased aortic valve, soon after the invention of extracorporeal circulation (ECC) by Gibbon in 1953 (Gibbon 1954). In 1962, Donald Ross in London, UK, and Brian Barratt-Boyes in Auckland, New Zealand, 
performed the orthotopic implantation of a cadaveric aortic valve almost at the same time and independently of each other (Barratt-Boyes 1964; Ross 1962). Before implantation, the cadaveric valves were sterilized and stored in an antibiotic cocktail for a few days to 6 weeks. In 1967 Donald Ross performed another pioneering operation, replacing a diseased aortic valve by means of the patient's pulmonary valve (autograft) and reconstructing the right ventricular outflow tract (RVOT) with a cadaveric aortic valve (homograft allograft), (Rubay et al. 1999). Marc O'Brien was first to implant cryopreserved human heart valves in 1975 . He published his results in 1987, demonstrating the preservation of valve viability using cryopreservation for freezing and storage in liquid nitrogen vapours (O’Brien et al. 1987).

Each year, approximately 2000 human heart valves (pulmonary, aortic and occasionally mitral), are transplanted in Europe (EDQM Newsletter 2018, Jashari et al. 2013). The main indications for the use of human heart valves are congenital valve malformation in neonates and infants, young females of reproductive age, athletes and patients with contraindications to the use of anticoagulant drugs, native or prosthetic valve endocarditis with annular abscesses, thromboembolic complications and bleeding risk after valve surgery.

In the late 1980s and beginning of 1990s, many cardiovascular tissue establishments (TEs) were established in different European Union Member States (EUMS). The aim of TEs was donor selection for cardiovascular tissues and the procurement, processing, storage and quality control of cardiovascular allografts. Currently, approximately 4000 TEs, of which approximately 20 are heart valve banks, active in the European Union (EDQM Newsletter 2018). The European Homograft Bank (EHB) was established in 1988 as an independent international TE with a nonprofit character. It has developed an international cooperation network involving many donation and transplantation centres in the EU and Switzerland (Jashari et al. 2013).

The European Commission and Council, the National Competent Authorities (NCA) and the TEs, in mutual collaboration, have approved and implemented a quality system for organ, tissue and cell transplantation that guarantees high quality and safety for both the donor and the patient, i.e., the human tissue graft recipient (EDQM 2019).
This paper is a review of 30 years of heart valve banking activity carried out in Brussels and its cooperation network for donation and transplantation. The long-term results and complications of transplanted allograft valves over time are presented. New incoming options are briefly discussed as the opportunities for improving quality and increasing durability of allograft valves.

\section{Material and methods}

Organization and structure

\section{Cooperation with donation and transplantation centres}

The cooperation network of our TE includes a large donation and transplantation hospital network in Belgium, EU, and beyond, working in partnership. The international donation network serves as the source of a large donor pool as the basis for the processing and storage of a notable number and large diversity of implantable allograft valves (of sizes and conduit lengths). The emergency and elective treatment of a considerable number of patients with heart valve problems is the final aim (Fig. 1).

\section{Infrastructure and critical equipment}

For the optimal evaluation of donated human body substances (hearts), a GMP (good manufacturing practice) facility for preparation ("manufacturing"), "processing") was constructed. This facility strictly meets our needs and is compliant with the EU recommendations/regulation and quality standards for cardiovascular tissue banking. Permanent monitoring of the work environment is performed accordingly (during rest and activity) (Euro-GTP 2007, Jashari et al. 2004; Klykens et al. 2013; Zahra et al. 2019a) (Fig. 2).

The long-term storage of allografts is possible using liquid nitrogen vapours (LNV) in extreme low temperature conditions (below $-130{ }^{\circ} \mathrm{C}$ ) after control rate cryopreservation in a Planer 560/16 system (Planer Limited, Middlesex, United Kingdom), with a computer guided program. This device represents a critical equipment for cardiovascular tissue banking (Fig. 3). 


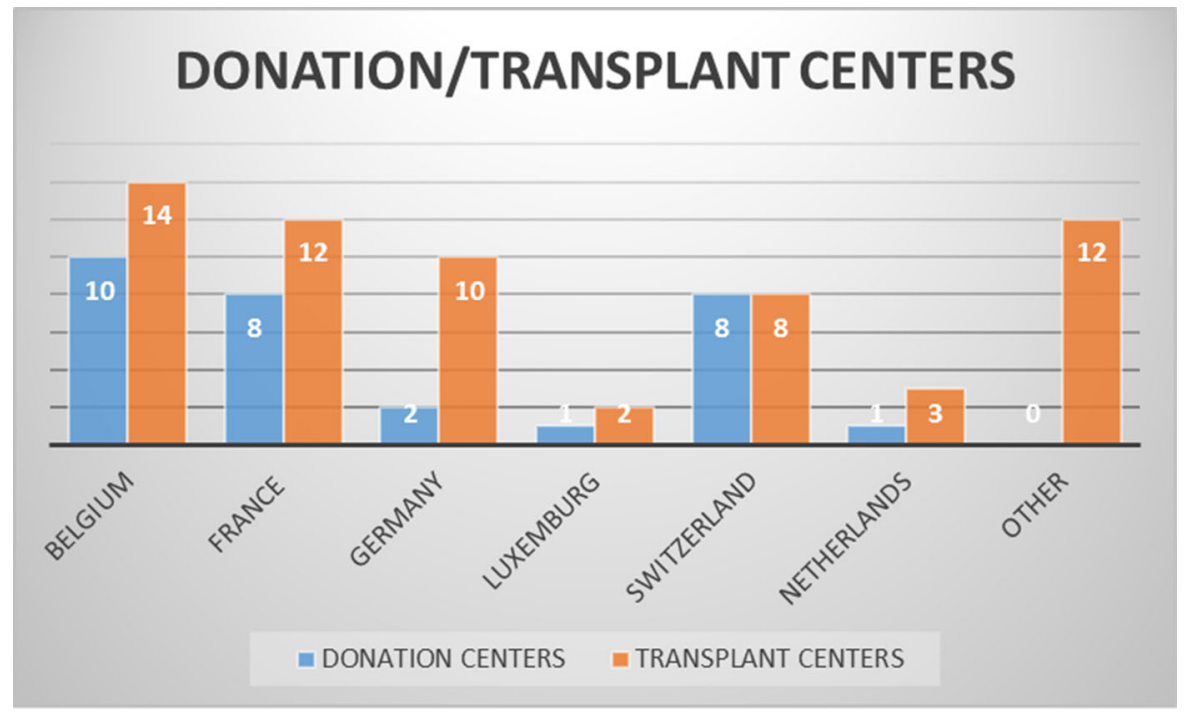

Fig. 1 Donation and transplantation cooperating network of EHB. The group "Other": only implanting centres without any donation activity

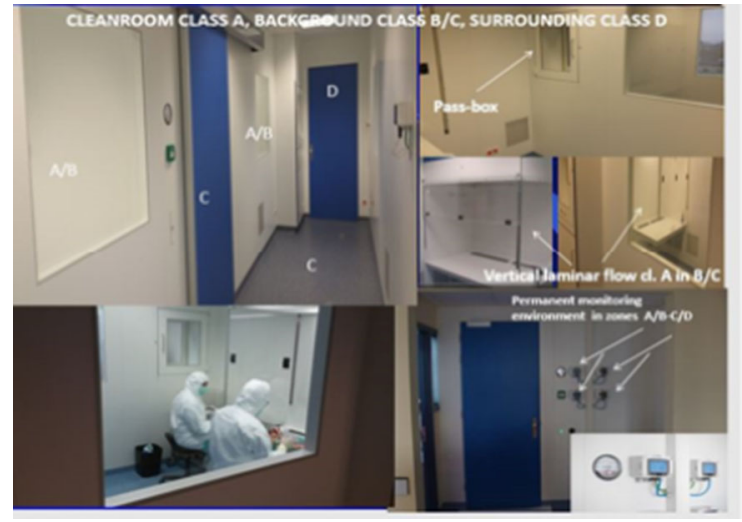

Fig. 2 Cleanroom (GMP/GTP), constructed in compliance with the EU Directives, EDQM recommendation and the Belgian Quality Standards for Tissue Banks (class A/B/C/D). GMP: Good manufacturing practice; GTP: Good tissue practices

Donation and processing

\section{Donor selection criteria and donor testing}

The donor exclusion criteria are based on donor age, clinical and behavioural history (social contact history, contact with toxic substances such as intravenous drug abuse, heavy metals, etc.), travel in some endemic areas (Ebola, Malaria, Tuberculosis, West Nile virus, Chagas disease, Q-fever, Zika or Dengue or a currently status of history of-, or contact with persons at risk for COVID-19). The donor exclusion criteria have been discussed in details in previous publications (Jashari et al. 2004, 2013).

For viral securitization, heart donors are tested for hepatitis B and C, HIV 1\&2, HTLV 1\&2 and syphilis. In the case of living donors with dilated cardiomyopathy, testing for Coxsackie viruses, is carried out as this group of viruses can provoke heart failure if infection occurs. Consequently, allografts from all Coxsackie-positive donors, are mandatorily discarded. During epidemics or pandemics (i.e. of Q-fever, West Nile virus, Ebola or COVID-19), the appropriate clinical and contact history assessment is mandatory, and the corresponding serological tests are selected in compliance with the international recommendations and national legislations.

Tissue donation, harvesting and shipment to the TE

Tissue recovery is carried out after verification of the status of donor consent, obtained either directly from the donor himself (living donor), consulting the national register (opposition or expression of consent to being a donor), or after discussion with the next of kin of the donor (after his death). In the EU, the majority of member states have adopted the "opt-out" system, meaning that each citizen is a potential donor. Currently in Belgium, in addition to the "opt-out" system, each citizen may decide whether he/she agrees that his/her donated body parts may also be used for 
A

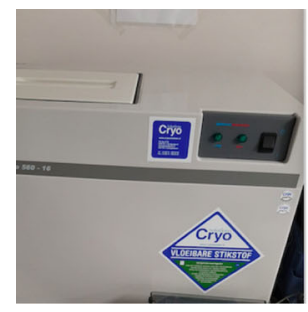

B

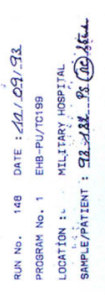

C

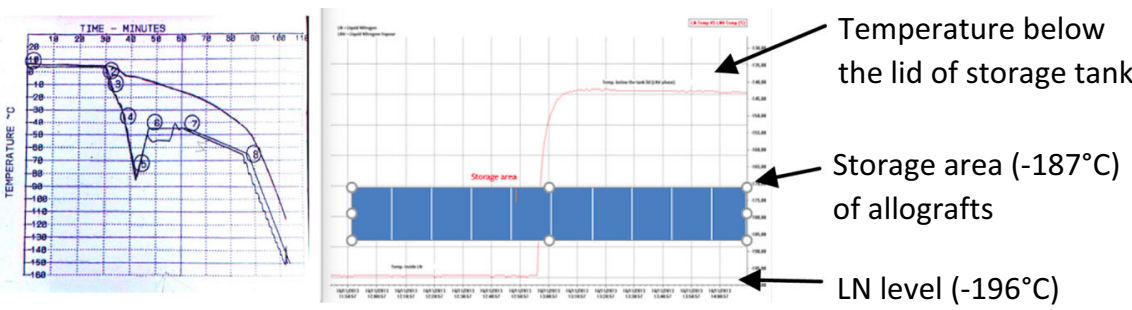

Fig. 3 Cryopreservation and storage of allografts: a Planer 560-16, b Cryopreservation curve for heart valves (control rate cryopreservation from $+4{ }^{\circ} \mathrm{C}$ to $-150{ }^{\circ} \mathrm{C}$ ), $\mathbf{c}$ Temperature conditions in the storage tank; LN: Liquid nitrogen

scientific research if not suitable for clinical application. The NCA has given more possibilities to citizens for the expression of consent for the use of their body parts after death (Royal Decree of 9 February 2020, published at "Staatsblad" 19 March 2020). Other member states of the EU have adopted another type of consent, the "opt-in"system, meaning that citizens need to explicitly express their consent to be a donor (consent for donation). Otherwise, their organs/tissues/cells are not considered suitable for transplantation after their death (Willis and Quigley 2014).

For the donor centres, the donation, harvesting and packaging procedures have been described in details by the TE (Jashari et al. 2004, 2013). Tissue harvesting is carried out in the operating room (OR) or in another space outside of the OR, which is specifically designed for this purpose. This space must have a controlled and monitored environment as well as laminar flow with air filtration by means of HEPA-filters. This is because harvesting of the heart in mortuary (which was usual practice in the majority of TEs in the $90 \mathrm{~s}$ ), resulted in a very high rate of donated cardiovascular tissue contamination (Goffin et al. 2000; Tabaku et al. 2004).

The usual and best approach for harvesting the heart is a median sternotomy, as it assures excellent visualization and access to the entire heart and great vessels. In the past, transdiaphragmatic access was used by some recovery teams (during abdominal organ recovery for transplantation), which resulted in a high discard rate due to inappropriate excision (cuts in the valve leaflets or tear of the right ventricular wall including the pulmonary valve), (Goffin et al. 2000; Jashari et al. 2013).

Rinsing of the recovered heart with saline solution and removal of all blood from its cavities prior to packaging can avoid bacterial growth during shipment to the TE. Packaging in a double sterile bag or pot filled with isotonic solution (saline $0.9 \%$, Ringer, Hartmann, etc.) and storage in a thermobox of polystyrene during shipment assures safe conditions until initiation of processing. This thermobox guarantees a temperature approximately $+4{ }^{\circ} \mathrm{C}$ for $24 \mathrm{~h}$. Accordingly, the shipment has to be accomplished with the shortest delay, optimally within $24 \mathrm{~h}$ from the recovery or cardiac arrest. The stability of temperature $\left(+4\right.$ to $\left.+8^{\circ} \mathrm{C}\right)$ in the thermoboxes has been validated for up to $24 \mathrm{~h}$ (internal, unpublished data).

For donor serological testing, the appropriate volume of blood needs to be collected before or during the recovery procedure. This sample joins the donated heart in the transport box. In the case of nonheart- beating donors, blood sample must be collected within $24 \mathrm{~h}$ of cardiac arrest.

\section{Reception and control of donated hearts}

Upon arrival at the TE, the packaging and labelling conditions are verified to determine whether they are compliant with the instructions of the TE, and the humidity, temperature and time of cardiac arrest are verified. Subsequently, the donor identity is anonymized, and the donor record is codified. The heart is (temporarily) preserved in cold conditions (below $+8{ }^{\circ} \mathrm{C}$ ) until the beginning of processing in the cleanroom. The blood samples are also controlled, centrifuged and prepared for sending to the laboratory for serological testing.

\section{Processing of heart valves in the TE}

As the ischaemic time for cardiovascular tissues is limited for preserving their quality, the processing of 


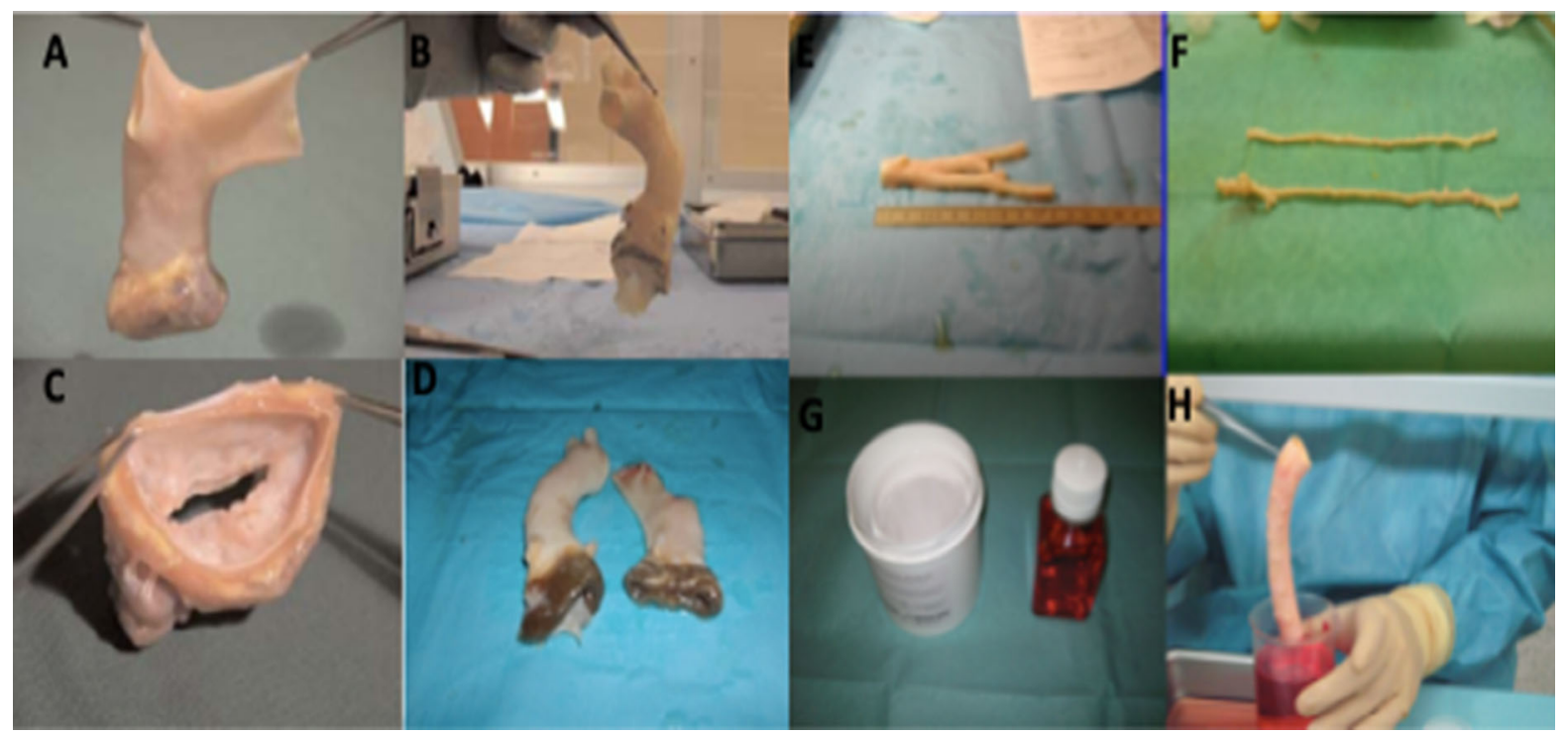

Fig. 4 Heart valves and vascular allografts after dissection and evaluation of morphology and function. a Pulmonary valve with whole conduit; b Aortic valve with ascending aorta and part of arch; c Mitral valve; d Aortic and pulmonary valve from the

donated hearts is carried out as soon as possible, optimally within $24 \mathrm{~h}$ of cardiac arrest. Dissection and evaluation of morphology and function is carried out in a class A cleanroom, with a class $\mathrm{B} / \mathrm{C}$ background, by the cardiac surgeon or trained medical assistant, who is assisted by the technical assistant.

Dissection of the heart, separation of the aortic and pulmonary valves and, eventually the mitral valve, evaluation of the morphology and function, and measurement of the size and length of vascular conduits are part of the assessment of the valves before their (provisory) acceptance for clinical application and preservation. The details of processing have been the subject of previous publications (Goffin et al. 2000; Jashari et al. 2004, 2013), (Fig. 3). Briefly, after evaluation of the morphology, the allograft is incubated in an antibiotic cocktail for decontamination for $40-48 \mathrm{~h}$ at $+4{ }^{\circ} \mathrm{C}$. Prior to immersion in antibiotics, samples are collected for quality testing in terms of histology and bacteriology. Microscopically, the structure (cells, collagen matrix) of allografts is evaluated, and infection and malignancy are excluded. The bacteriological tests must exclude the presence of any contaminant strains (bacterial/fungal) in the tissues before their release for clinical application. The sterility tests are performed before and after incubation in antibiotics. For decontamination same donor heart; e aortic bifurcation with iliac arteries; $\mathbf{f}$ two superficial femoral arteries; $\mathbf{g}$ antibiotic cocktail for decontamination; $\mathbf{h}$ thoracic aorta after decontamination (ready for cryopreservation)

purposes, an antibiotic cocktail is used. It is composed of vancomycin, lincomycin and polymyxin B at low concentrations. The incubation temperature is $+4{ }^{\circ} \mathrm{C}$ (Diaz Rodriguez et al. 2016; Goffin et al. 2000). After validation, in May 2019, we implemented a closed testing technique using the BACTEC Blood Culture System for the incubation and testing of tissues and fluids (transport, cryopreservation) (Jashari et al. 2021).

Following decontamination, the allograft is placed in a cryopreservation solution (10\% dimethyl sulfoxide in RPMI (Roswell Park Memorial Institute, USA)) and double-packaged for cryopreservation. Cryopreservation is carried out in a Planer 560-16 system (Planer Limited, Middlesex, United Kingdom) with controlled-rate freezing (Fig. 4). As soon as cryopreservation is completed (approximately $2 \mathrm{~h}$ ), the allograft is moved to the storage tank in liquid nitrogen vapour (Fig. 5). The shelf life of cryopreserved allografts is 5 years (as recommended by the EU Directive and the NCA). A recent study by a group from the CV Tissue Bank of Prague has demonstrated that the storage of cardiovascular tissues in liquid nitrogen vapour can be prolonged for several more years if the storage conditions remain stable during the whole period of storage (Burkert et al. 2020). 


\section{Quality control and release of allografts}

The responsible person at the TE authorizes the release of allografts for clinical application. For this, the following criteria have to be met:

- Donor clinical and behavioural history must be in compliance with tissue regulations

- Serological tests of the donor samples must show freedom from viral infection

- Morphology and function of allografts must be within acceptable criteria

- Histological examination must show normal structure (extracellular matrix), no presence of infection, no malignancy (Fig. 6)

- At the final testing, allografts must be free of any bacterial or fungal contamination

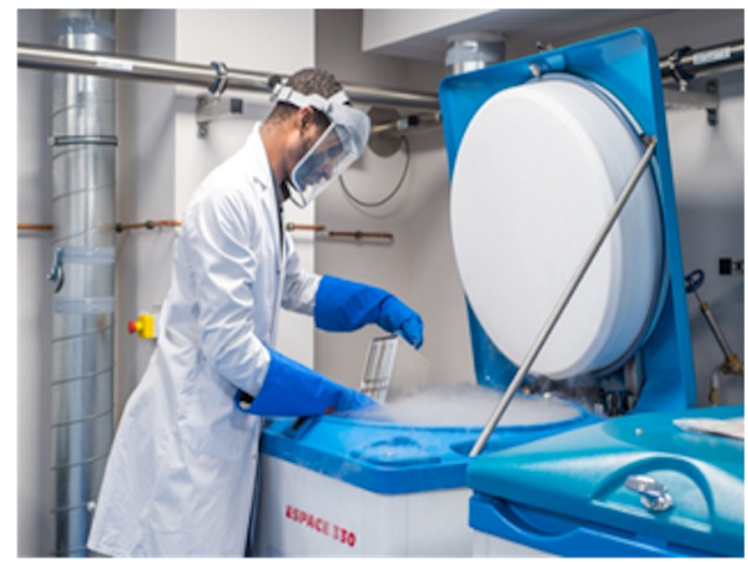

Fig. 5 Cryogenic area with storage tanks filled with liquid nitrogen (LN), containing cryopreserved and stored allografts
- Cryopreservation curve must be within the acceptable criteria as predicted by the TE protocol

- Storage conditions (temperature, environment) must be optimal (below $-130{ }^{\circ} \mathrm{C}$ ) throughout the period of storage (permanent monitoring evidence).

Validation of tissue bank procedures

Initially, various procedures for quality assurance used in the TEs, were implemented empirically (from own experience or experience of other TEs) or relying on the advice of experts in the field (pathologists, clinical biologists, surgeons, etc.). At that time, the tissue banking activity was covered by the regulation for organ transplantation (in Belgium, law of 1986 regarding organ transplantation). However, in 2004, the European Commission, in cooperation with experts in the field from the EUMS, proposed and adopted the Tissue Directive, i.e., Directive 2004/23/ EC regarding the quality standards for the selection, procurement, processing, preservation, storage and distribution of human tissues intended for human application. In 2006, two new (technical) directives were endorsed by the EC and Parliament regarding the technical requirements and process for notification of a serious adverse events or reaction (SAE/R) provoked by human tissue used for human application (Commission Directive 2006/17/EC; Commission Directive 2006/86/EC). Accordingly, the tissue banking regulation was separated from the organ transplantation regulation. As transplanted organs are "lifesaving" for
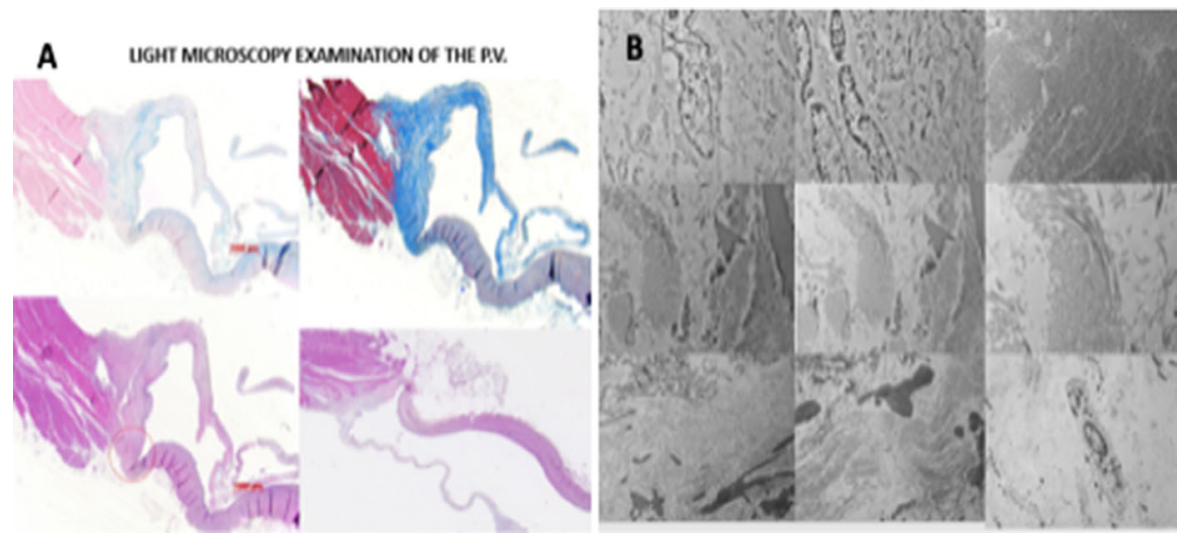

Fig. 6 A: Light microscopic evaluation of the pulmonary valve after thawing, showing preserved structure; B: Transmission electron microscopy showing well preserved and intact collagen matrix as well as cellular elements 
the patient and transplanted tissues are "life-improving" for the patient, tissue regulation must follow the principle of posing no risk to the patient, in contrast to organ regulations, which follow the principles of an acceptable minimal risk. Hence, the testing of tissue donors is stricter than that of organ donors (i.e., NAT $\mathrm{HIV} / \mathrm{HBV} / \mathrm{HCV}$ and HTLV became mandatory for tissues but not for organs).

In compliance with the Belgian and European Tissue Banking regulations, the EHB has validated a variety of procedures (i.e., residual antibiotics or residual cryopreservation solution (DMSO) in allografts, bacteriological testing, etc.), (Diaz Rodriguez et al. 2017; Fan et al. 2012; Jashari et al. 2007, 2011, 2021).

\section{Results}

Donation

The first donated hearts arrived in our TE in 1989 (Jashari et al. 2004). Over 30 years, 7290 nontransplantable heart, were harvested and sent to our TE from the donation network in Belgium, France, Luxemburg, the Netherlands, Germany and Switzerland. Donation activity increased significantly over time (1934, 2566 and 3062 hearts were donated during the first, second and third decades, respectively). The donation activity increased by 32.7 and $19.3 \%$ during the second and third decades, respectively, compared to the previous decade (Fig. 7).

For a long time, the acceptable donor age limit for heart valves was 65 years for both sexes, as presented in the past (Belgian Law of 1986. Jashari et al. 2013) (Fig. 8). The organ donor age has increased in Europe during the last decade, depending on the physical conditions of the donor and the type of donated organ or tissue intended for transplantation. In 2016, our TE increased the donor age limit to 70 years (only for pulmonary valves) after validation (internal, unpublished data). Our validation process followed previously published results by the German Heart Center in Berlin using pulmonary valves from donors of up to 70 years of age. This study reported optimal function of the PVs of donors between 65 and 70 years of age (Grosse et al. 2008).

\section{Processing and control}

Following the quality control process in our TE, between 50 and $60 \%$ of heart valves are discarded each year due to morphology, contamination, surgical cuts or other reasons (Fig. 9). As the donor age limit was increased to 70 years for pulmonary valves, the number of valves discarded for morphological reasons has increased significantly in recent years (mainly aortic valves) compared to previous decades (Table 1). This table also shows a notable decrease in surgical

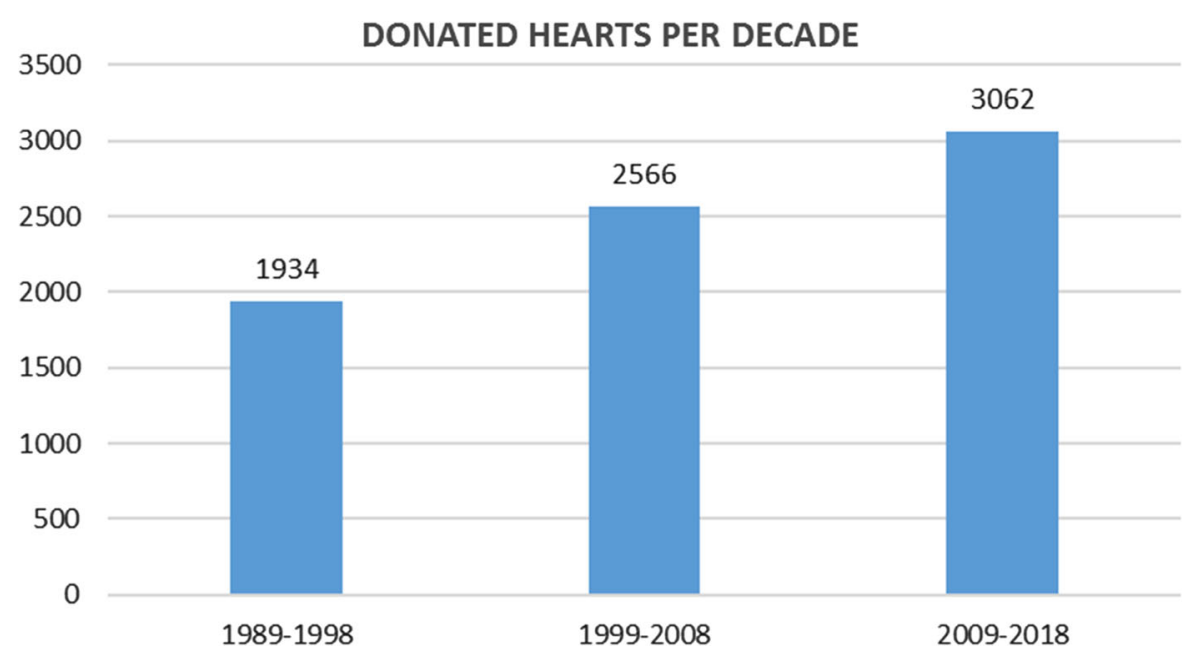

Fig. 7 Donations per decade. A total of 7562 hearts with distribution per decade: first with 1934, second $2566(+32.7 \%)$ and third $3062(+19.3 \%)$ increase comparing to the previous decade 
Fig. 8 Age of the heart donors (in 2016, 2017 and 2018). $83.5 \%$ belong to the age groups between 45 and 70 years whereas $16.5 \%$ to the younger donors (0-44 years)

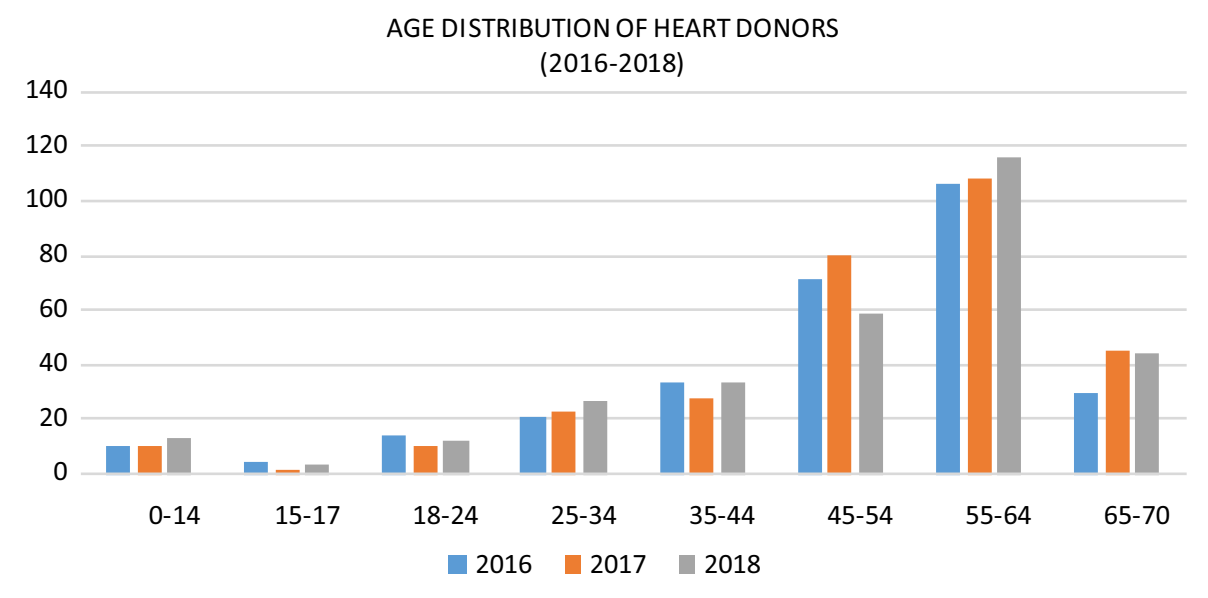

REASONS FOR DISCARDING VALVES (2017: 50\% DISCARDED)

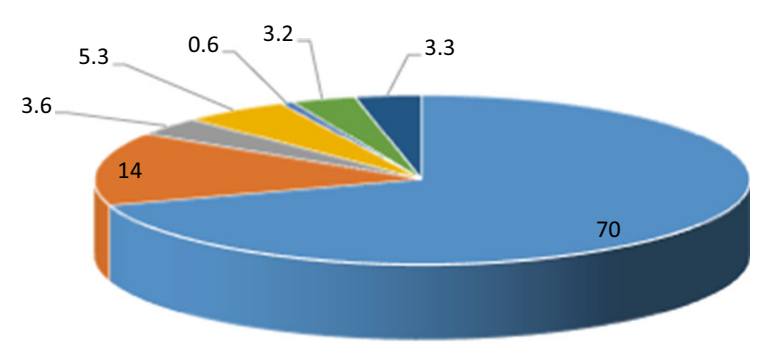

= Morphology $=$ Bacteriology $=$ Surical cut $=$ Med. Story
= Viral risk $=$ Histology $=$ Techn. error

Fig. 9 Discarded valves for: morphology $70 \%$, contamination $14 \%$, surgical cut $3.6 \%$, medical history $5.3 \%$, technical error $3.3 \%$, histology $3.2 \%$ and viral risk $0.6 \%$

damages to harvested hearts during the last decade (3.9\%) compared to the first and second decades (10.6 and $8 \%$ of damaged valves, respectively). This issue was repetitively discussed with the recovery teams and transplant coordination teams of our network. Accordingly, the suspected inappropriately excised hearts were deferred prior to their shipment to our TE.

Among the most demanded pulmonary valves (PVs) for paediatric patients are those with small diameters (between 10 and $20 \mathrm{~mm}$ ). Due to the limited number of donors of a very young age, in the past, we were not always able to meet the demands with the appropriate allograft for some neonates and very young patients. Accordingly, as an alternative to small PVs, the construction of a small bicuspid valve from either a large normal PV (25-30 $\mathrm{mm})$ or a valve with one unacceptable leaflet (i.e., large fenestrations with inappropriate competence test result, surgical cut at recovery) and two normal leaflets was suggested to the surgeons. Bicuspidized PVs have become an attractive solution for the treatment of neonates and infants with congenital valve malformations. Accordingly, some surgeons in our network, in the absence of small tricuspid PV allografts, systematically use the bicuspidized PVs. This has become a routine procedure for

Table 1 Overview of reasons for discarding valves per decade (\% per decade and mean)

\begin{tabular}{llllc}
\hline & $1989-1998(\%)$ & $1999-2008(\%)$ & $2009-2018(\%)$ & Mean $(\%)$ \\
\hline Morphology & 50.6 & 68.6 & 73.2 & 64.1 \\
Contamination & 7.8 & 11.8 & 14.7 & 11.4 \\
Cut at recovery & 10.6 & 8 & 3.9 & 7.5 \\
Viral risk & 4.4 & 2.9 & 1.3 & 2.9 \\
Histology & 0 & 5 & 0.5 & 1.8 \\
Technical error & 1 & 1 & 0.7 & 0.9 \\
\hline
\end{tabular}

It is obvious increase of discard after the donor age increase to 70 years (last decade) 
some of them during the past 15 years. The paediatric cardiac surgery team of the University Hospital of Leuven, Belgium, has reported acceptable mid-term performance of bicuspidized PVs, comparable to the results of normal tricuspid PVs (Urso et al. 2012). The predominant size of the pulmonary valves delivered from our TE is between 23 and $29 \mathrm{~mm}$.

Similar to pulmonary valves, there is a lack of paediatric sizes of aortic valves (AVs) (between 10 and $18 \mathrm{~mm}$ ). Furthermore, aortic valves with diameters above $26 \mathrm{~mm}$ are not often available, as large AVs are usually atheromatous and are discarded during the morphological evaluation. Some of the initially accepted and stored AVs are eliminated later on during storage, although they fulfil the quality criteria. However, as they do not meet the size requirements of surgeons (aortic valves with diameters between 19 and $22 \mathrm{~mm}$ are used only exceptionally), the probability of implantation for these valves is minimal. Figures 10 and 11 show the diameters of aortic and pulmonary valves, processed in our TE in 2016, 2017 and 2018.

\section{Distribution and transplantation}

Seven thousand two hundred ninety heart valves (pulmonary, aortic and mitral), were distributed for transplantation over 30 years. Similar to donations, transplantation activity increased significantly between the first, second and third decades (2050, 2550 and 2690 valves were transplanted in the first, second and third decade, respectively). There was an increase of 24.4 and $5.5 \%$ during the second and third decades, respectively, compared to the previous decade (Fig. 12, Table 2). A total of 4475 pulmonary (61.4\%), 2760 aortic (37.9\%) and 55 mitral valves $(0.7 \%)$ were distributed for transplantation.

Regarding the position of the transplanted valves, right ventricular outflow tract reconstruction (RVOTR) increased by $51 \%$ during the second decade and by $16 \%$ during the third decade, compared to the previous decade. In contrast, left ventricular outflow tract reconstruction (LVOTR) activity decreased by 19.7 and $19.6 \%$ during the second and third decades, respectively, compared to the previous decade.

The number of transplanted mitral valve (MV) allografts is very limited due to the complex morphology of the mitral valve and unsatisfactory mid- to long-term results (Kalangos et al. 2011). Only 9, 39 and 7 mitral valves were distributed and transplanted during the first, second and third decades, respectively. As the implantation of mitral valves decreased in the last decade (only 7 mitral transplantations), we have stored only a limited number of these valves over the last 5 years (and some 20 for research purposes).

The "Ross operation" showed a notable increase during the second decade compared to the first decade, accounting for 956 transplantation during the second decade versus 424 during first the decade (an increase of $125.5 \%$ ). In contrast, this operation showed a slower increasing tendency during the third decade (a total of 1030 transplantations or an increase of $7.7 \%$ compared to the second decade). To summarize, for this demanding operation a total of 2410

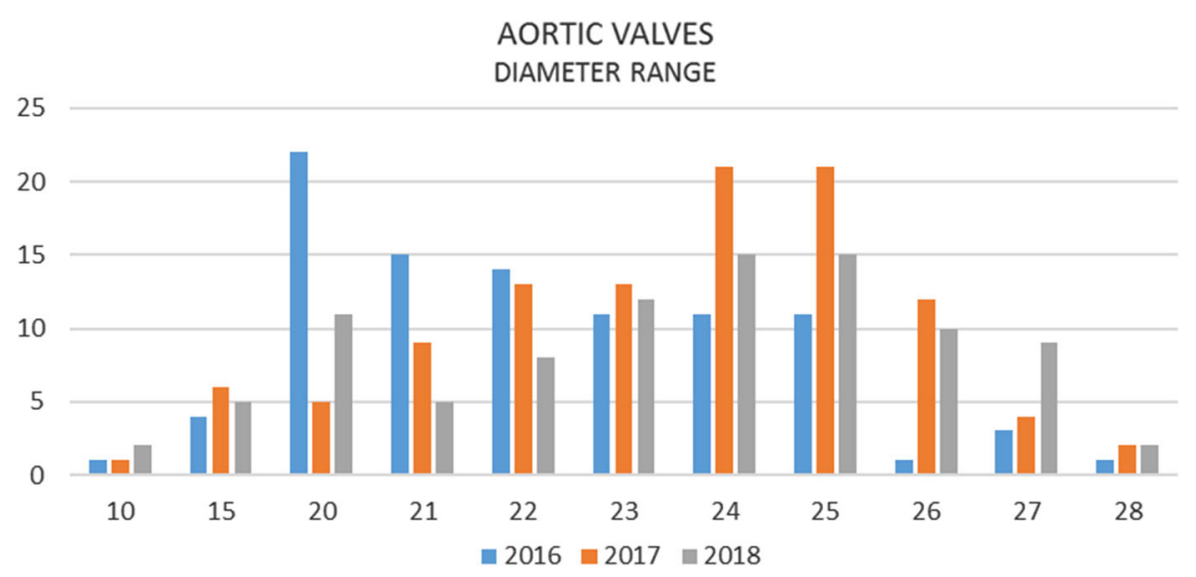

Fig. 10 Diameter range of the aortic valves (2016, 2017 and 2018). The predominant diameters are between 20 and $26 \mathrm{~mm}$. Only few AVs are of paediatric sizes $(10 \mathrm{~mm}$ : only 1 in 2016 and 2017, respectively and 2 in 2018, whereas those of $15 \mathrm{~mm}: 4$ in 2016, 6 in 2017 and 5 in 2018) 


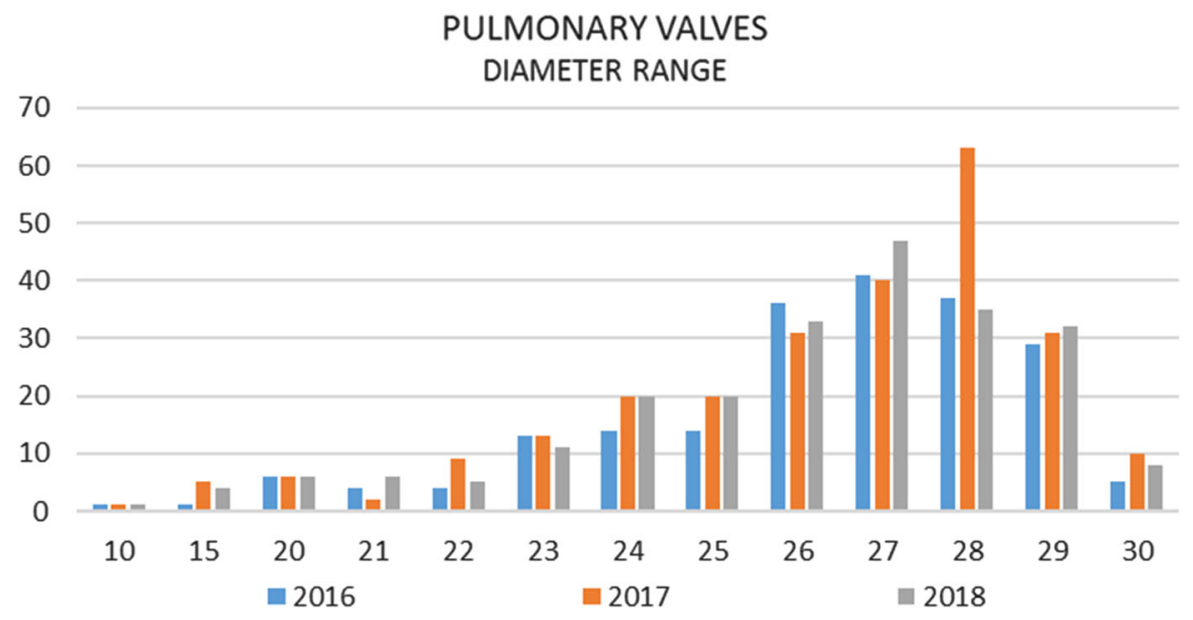

Fig. 11 Diameter range of the pulmonary valves (2016, 2017 and 2018). The predominant diameters are large "adult" valves and very few paediatric (10-20 mm): only 1 pulmonary valve of
$10 \mathrm{~mm}$ in respective 2016, 2017 and 2018, whereas 1,3 and 2 with diameter of $15 \mathrm{~mm}$ in 2016, 2017 and 2018, respectively

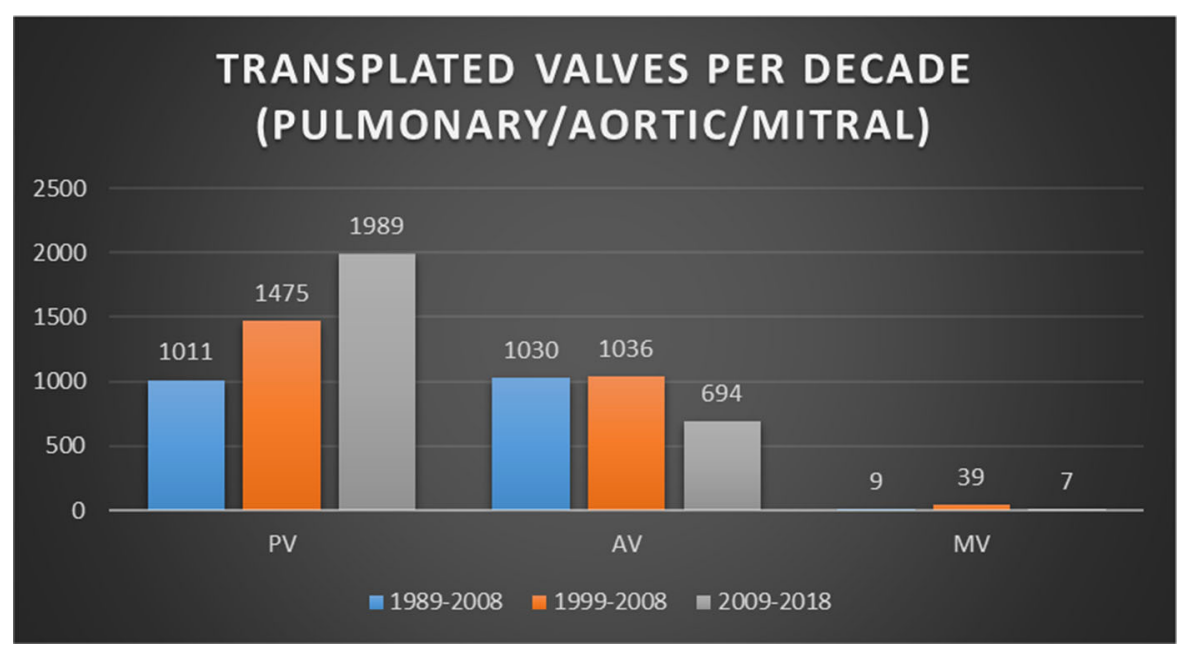

Fig. 12 Transplantation of heart valves per decade (1989-2018). PV: pulmonary valve; AV: aortic valve; MV: mitral valve

cryopreserved allograft valves have been distributed so far (Table 2).

Another important indication for the use of cryopreserved allograft valves is valve endocarditis with severe complications (annular abscess, leaflet destruction or vegetation), as the infection rate of transplanted allografts is very low when implanted under conditions of infection (Flameng et al., 2015; Solari et all. 2016). A total of 1011 cryopreserved allograft valves were distributed for the treatment of endocarditis of the aortic, pulmonary, mitral or tricuspid valve (native or prosthetic). At present, endocarditis is the principal indication for the use of cryopreserved aortic valves in adult patients.

Eight-hundred fifty-seven AVs were distributed and transplanted in the RVOT, showing a notable increase in transplantations during the second decade (298 vs. 387 or increase of $30 \%$ ). In contrast, only 172 AVs were transplanted during the third decade, indicating a decrease of $44.4 \%$ compared to the previous decade.

In the beginning of the distribution of cryopreserved allograft valves, 76 cryopreserved PVs were used for reconstruction of the LVOT. Due to signs of structural valve failure (SVF), all these valves were 
Table 2 Transplantation of heart valves (7290) per position and indication

\begin{tabular}{|c|c|c|c|c|}
\hline Position & 1989-1998 & 1999-2008 & 2009-2018 & TOTAL \\
\hline \multicolumn{5}{|c|}{ Transplantations per decade } \\
\hline RVOT & 1233 & $1862(+51 \%)$ & $2161(+16 \%)$ & 5256 \\
\hline AV & 298 & 387 & 172 & 857 \\
\hline PV & 935 & 1475 & 1989 & 4399 \\
\hline ROSS & 424 & $956(+125.5 \%)$ & $1030(+7.7 \%)$ & 2410 \\
\hline LVOT & 808 & $649(-19.7 \%)$ & $522(-19.6 \%)$ & 1979 \\
\hline AV & 732 & 649 & 522 & 1903 \\
\hline PV & 76 & 0 & 0 & 76 \\
\hline ENDOC & 281 & $387(+37.7 \%)$ & $343(-11.4 \%)$ & 1011 \\
\hline MV & 9 & 39 & 7 & 55 \\
\hline Total & 2050 & $2550(+24.4 \%)$ & $2690(+5.5 \%)$ & 7290 \\
\hline
\end{tabular}

RVOT right ventricular outflow tract, $L V O T$ left ventricular outflow tract, $A V$ aortic valve, $P V$ pulmonary valve, Ross operation following Donald Ross, using pulmonary autograft for replacement of diseased aortic valve and reconstruction of RVOT with pulmonary or aortic allograft, $M V$ mitral valve, Endoc Treatment of infective valve endocarditis

explanted within the first 5 years of implantation. Due to the poor results of these valves implanted in the LVOT, cryopreserved pulmonary valves have been used only for implantation in the RVOT position since 1995 (Table 2).

The allocation procedure of cryopreserved allograft valves follows two main criteria: a) the clinical indication and $b$ ) the state of emergency of the patient. Following the demand introduced by the implanting surgeon or his administration, the medical director of the TE selects and proposes the best available valve at that moment. The surgeon, after analysing the description (release statement), approves it for clinical application (or disapproves, if it does not meet his expectations), as he is ultimately responsible for its implantation. The surgeon also indicates the place and time of delivery of the allograft.

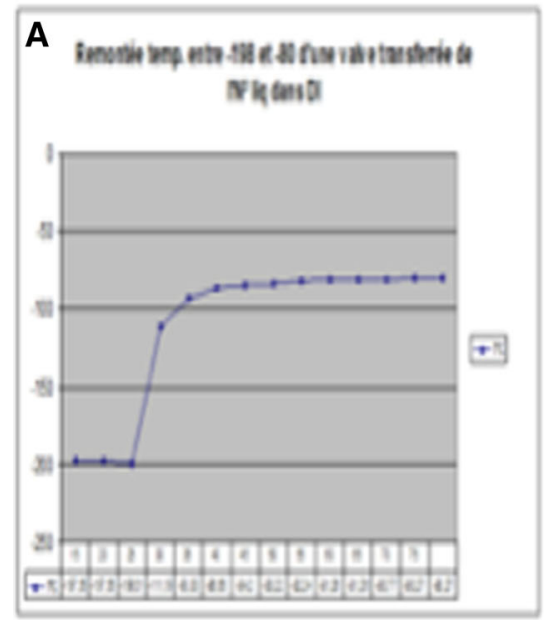

Shipment in Dry Ice (DI); temo $-76^{\circ} \mathrm{C}$
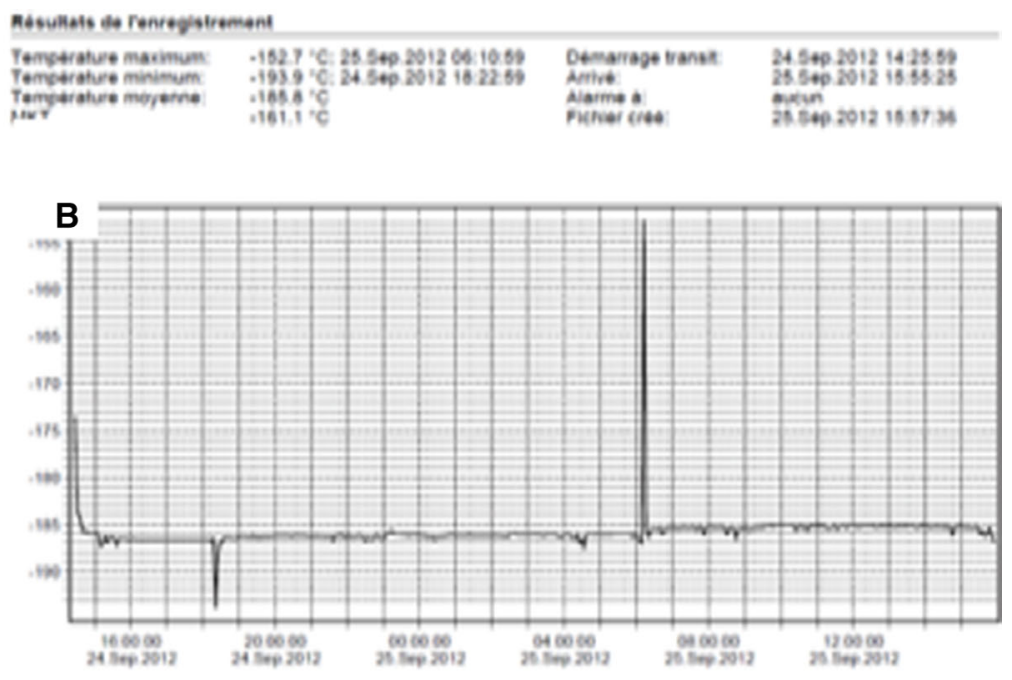

Shipment in Dry Shipper (DS) at below $-130^{\circ} \mathrm{C}$

Fig. 13 Monitoring of temperature during shipment of allografts (A: dry ice, temperature $-76{ }^{\circ} \mathrm{C}$; B: dry shipper, temperature below $\left.-130{ }^{\circ} \mathrm{C}\right)$ 
The shipment to the implantation centre is carried out in dry shipper (DS) at temperatures below $-130{ }^{\circ} \mathrm{C}$. Only occasionally is shipment in dry ice (DI) at $-76{ }^{\circ} \mathrm{C}$ used. The temperature is monitored permanently during the whole trajectory of shipment by means of a temperature logger, installed on the lid of the DS (Fig. 13). The allograft shipped in the DS can return to the TE if it is not used and the DS remains intact (with an acceptable temperature curve, verified at the moment of the return of the DS). In contrast, if the DS was opened or there was a temperature fluctuation, the allograft may not be stored anymore in the storage tank with LN and has to be destroyed. Each year approximately $0.5-1 \%$ of all distributed allografts must be destroyed due to an unacceptable temperature curve (DS opened by personnel in the OR or monitoring failure), (internal, unpublished data).

In the case of shipment of cryopreserved allografts in DI, they may not be returned to the TE for further storage, as the temperature of DI $\left(-76^{\circ} \mathrm{C}\right)$ exceeds the critical temperature (approximately $-123{ }^{\circ} \mathrm{C}$ ) at which microcrystals might be generated in the allograft matrix and provoke irreparable damage ("fractures" or “cracks"), (Wassenaar et al. 1995). Due to fragilization with ice crystals, the risk of immediate rupture after implantation or premature calcification of allografts is important. If not used and not thawed, the cryopreserved allograft may be stored at the implanting centre for a short duration (one to a maximum of three months) in the freezer at $-80{ }^{\circ} \mathrm{C}$ under the responsibility of the implanting surgeon.

Together with the allograft, the TE sends to the implanting surgeon the accompanying record of the donor/allograft including the following:

- Release statement including the donor information (age, cause of death, place, date and hour of harvesting, processing data, specification of allograft, quality test results (bacteriology, histology, serology, cryopreservation) and description of morphology

- Protocol of thawing and DMSO dilution for implanting surgeon (followed very strictly, as it may seriously damage valves, with possibly catastrophic consequences)

- Notification of any important non-conformity information that the surgeon needs to know about the allograft
- Traceability document of transplantation.

\section{Traceability of transplantation, discharge and follow-up information}

The implanting surgeon is requested to complete and return to the TE the "Traceability sheet" document, confirming the transplantation but also giving his expert's opinion about the quality of the allograft. To date, $99 \%$ of these documents are sent back on the day of surgery or during the week of transplantation. One month after transplantation, the surgeon is requested to send a second document, the "Discharge form", which is received by our TE in approximately $45-50 \%$ of all implantations (internal, unpublished data) as it is not a legal obligation. The information requested by means of this document concerns the early performance of allografts (at the moment of patient discharge), including the findings of an echocardiography control examination of valve function.

Regarding the long-term outcome, so far TEs have not been legally obliged to have this information in their possession. Consequently, complete FU data are often not available. However, multiple studies (monocentric or multi-centric) have been carried out either on our initiative, or on the initiative of the implanting teams. The aim of these studies was to assess the outcome of transplanted valves, showing their early-, mid- and long-term performance (Dekens et al. 2019; Flameng et al. 2015; Hechadi et al. 2013; Meyns et al. 2005; Solari et al. 2016). Both partners, i.e., our TE and the transplanting surgical teams, contributed to these studies.

\section{Long-term outcome of transplanted cryopreserved allograft valves}

Despite the missing important long-term FU information of the transplanted allograft valves, some valuable information has been obtained through these studies. One such study concerns reconstruction of the RVOT with a pulmonary valve. This study was performed in cooperation with one of our partners, and it was published in 2005. It revealed an important difference in the long-term outcome of valves implanted in 
newborns and infants (0-10 years) and those implanted in adult patients (Meyns et al. 2005). The first group of patients showed early SVF, whereas in adult patients, the outcome was outstanding. Likewise, a study carried out in cooperation with another partner and published in 2019 showed better outcomes of pulmonary valves in cases with than without $\mathrm{ABO}$ group matching between the patient and the donor (Dekens et al. 2019).

The long-term result of the treatment of endocarditis with cryopreserved allograft valves was studied as well, as allograft valves offer the best solution for very complex cases of endocarditis (Flameng et al. 2015; Solari et al. 2016). Studies carried out by two Belgian university hospitals, have shown excellent results regarding re-infection (5.3 and 7\% recurrent endocarditis in 10 years of FU, respectively). In contrast, SVF after 10 years of FU was reported in both studies (13.7 and $40 \%$, respectively).

\section{Financial aspects of the tissue banking}

The clinical application of human tissues in the EUMS has become a "standard surgical procedure" over three decades. Cryopreserved allograft valves represent the "gold standard" for some indications. Accordingly, competent authorities and health care insurance agencies have listed allograft valves among the routinely used valves, with $100 \%$ reimbursement by healthcare insurance.

\section{Serious adverse events and reactions (SAE/Rs)}

Various SAE/Rs have been reported after being detected in either the TE or the implanting centre. Table 3 highlights these complications. Four cases of positive bacterial control of allografts at the moment of transplantation, were reported by the implanting surgeons. All four were pulmonary valves used for RVOTR. Staphylococcus aureus (2 cases), Aspergillus and Enterococcus, were isolated in the culture of the pulmonary trunk samples. None of these patients developed clinical symptoms of valve infection. Furthermore, no confirmation of valve infection was obtained by blood culture or by echocardiography. These cases were investigated in cooperation with the implanting surgeons and respective laboratories of clinical biology. The common conclusion for all four cases was that the test samples might have been contaminated, either in the operating theatre or in the laboratory.

Two cases of endocarditis were reported after pulmonary allograft transplantation for the "Ross operation". In the first case, the pulmonary valve was thawed but not implanted the same day. It was stored in physiologic solution and refrigerated at $+4{ }^{\circ} \mathrm{C}$ until the next day, when implanted. In the early postoperative period, the patient developed endocarditis with Candida albicans as a contaminant. There was very strong supposition of allograft contamination during manipulation in the operating theatre. The second case of pulmonary valve endocarditis occurred in 2017 with a pulmonary valve, which tested positive for Klebsiella in the initial control but it was sterile on final testing (after $48 \mathrm{~h}$ of incubation in antibiotic cocktail). No other valve was available at the moment of demand, and the patient required semi-urgent surgery. Both patients underwent re-operation, both received a new cryopreserved allograft valve, and both survived the re-operation. Table 3 highlights all SAE/ Rs recorded in our TE.

\section{Current and future developments in human heart valve banking}

Despite some banking issues, cryopreserved allograft valves remain the best clinical options for many complex cardiac reconstructions. They are the most flexible option for complex ventricular reconstruction in neonates, infants and young adults (Hopkins 2006). However, many studies on the mid- to long-term performance of these valves have demonstrated a tendency of accelerated deterioration after transplantation, particularly in newborns, infants and younger patients. Several authors have reported immunerelated complications (rejection) as an important factor (Baskett et al. 2003; Dekens et al. 2019; Hopkins 2006; Meyns et al. 2005; Rajani et al. Rajani et al. 1998). In addition, the initially preserved viability of cryopreserved allograft valves disappears soon after implantation, resulting in acellular scaffolds, prone to SVF and calcification (Hopkins 2006). Accordingly, researchers and cardiac surgeons have developed tissue-engineered allograft valves as a possible solution (Cebotari et al. 2010; da Costa 
Table $3 \mathrm{SAE} / \mathrm{Rs}$ detected either in the TE or at implanting centres

\begin{tabular}{|c|c|c|}
\hline SAE/SAR & VLV & Comments and consequences \\
\hline $\begin{array}{l}\text { Internal pouch taken in the sealing } \\
\text { line of external pouch }\end{array}$ & 1 & $\begin{array}{l}\text { Difficulties during the opening of the pouch with allograft (at implanting centre) with } \\
\text { the contamination risk. Reported to EHB as SAE; no consequences for patient }\end{array}$ \\
\hline Interruption of cryopreservation & 1 & $\begin{array}{l}\text { Cryopreservation interrupted at }-100^{\circ} \mathrm{C} \text {. Problem appeared due to low level of LN } \\
\text { in the Ranger (feeding of Planner). Several allografts discarded }\end{array}$ \\
\hline Allograft lost in storage tank & 2 & $\begin{array}{l}\text { Allografts fallen in the liquid nitrogen (behind the storage racks); they were found } \\
\text { during disinfection of the storage tank; no direct consequences for patients; } \\
\text { allograft eliminated due to the contact with liquid nitrogen }\end{array}$ \\
\hline $\begin{array}{l}\text { Return to the stock: not indicated } \\
\text { position in storage tank }\end{array}$ & 1 & $\begin{array}{l}1 \text { valve "lost" in the storage tank after returning from the implanting centre. } \\
\text { Technician did not indicate location. Found later on during preparation of other } \\
\text { allografts for sending for implantation }\end{array}$ \\
\hline Storage tank submerged with LN & 25 & $\begin{array}{l}\text { Due to a technical defect, the valve of the automatic filling system did not stop and } \\
\text { the tank continued filling until the morning. Despite the fact that histology } \\
\text { examination of some valves/arteries of this group did not show any damaging } \\
\text { effect, all } 25 \text { allograft valves were discarded (decision of the Board of EHB). } \\
\text { Insurance covered } 90 \% \text { of financial loss }\end{array}$ \\
\hline \multirow[t]{2}{*}{ Mix up of distributed valves } & $2 \mathrm{x}$ & $\begin{array}{l}\text { 1st case: } 2 \text { PV with approximately same diameters sent to two Belgian Hospitals. } \\
\text { Surgeon of one centre discovered it and did not use the received allograft. In } \\
\text { emergency } 2 \text { nd valve was sent to him and it was successfully implanted. Surgeon } \\
\text { from the other center successfully implanted valve he received (specifications } \\
\text { almost same as by him requested valve) }\end{array}$ \\
\hline & & $\begin{array}{l}\text { 2nd case: AV send to the centre that ordered PV and opposite: discovered in one of } \\
\text { centres before starting surgery. Both operations re-scheduled and one (aortic) valve } \\
\text { eliminated as it was already thawed; the other one returned back to stock }\end{array}$ \\
\hline Cracks in allograft & 2 & $\begin{array}{l}\text { Valves were not correctly thawed (EHB thawing protocol was not respected); } \\
\text { surgeon called to EHB and was instructed not to use allograft; implanted } \\
\text { bioprosthetic valve in both cases }\end{array}$ \\
\hline Acute, non-fatal bleeding & 3 & $\begin{array}{l}3 \text { cases, re-intervention; either sutured bleeding place or replacement by } 2 \text { nd } \\
\text { allografts/bioprosthesis }\end{array}$ \\
\hline Infection & 2 & $\begin{array}{l}2 \text { PV: valve endocarditis; replacement with new allograft; both patients survived } \\
\text { intervention }\end{array}$ \\
\hline \multirow[t]{2}{*}{$\begin{array}{l}\text { Control of sample from valves after } \\
\text { thawing }\end{array}$} & 4 & $\begin{array}{l}3 \text { PV consecutively implanted in the same centre within one month: } 3 \text { consecutive } \\
\text { valves tested positive }(2 \times \text { staphylococcus aureus; } 1 \times \text { aspergillus); clinically } \\
\text { patients did well, no signs of infection, echocardiography was normal; investigation } \\
\text { revealed work around the lab that might have provoked contamination in the lab }\end{array}$ \\
\hline & & $\begin{array}{l}\text { Another case reported by a second centre, sample taken from the pulmonary valve } \\
\text { tested positive for Enterococcus. Patient showed no signs of infection, } \\
\text { echocardiography showed no endocarditis. Patient left hospital on day } 10\end{array}$ \\
\hline Cancer transmission & / & No reports \\
\hline Sero-conversion of patient & l & No reports \\
\hline Death immediately after surgery & / & No reports \\
\hline
\end{tabular}

$L N$ liquid nitrogen, $N P C$ non-valvular pulmonary conduit, $P V$ pulmonary valve, $V L V$ valves

et al. 2010; Hopkins 2006). Data from some clinical studies in the USA published during the last decade strongly support this development (Hopkins 2006). Ideal valves meet the following conditions: they elicit no foreign body response; they are non-immunogenic; they contain viable cells; they are non-thrombogenic and they are capable of growing with the patient
(Hopkins 2006). In Europe, following the experience of the Hannover Medical School with cell-free valve allografts in an animal model (sheep) and after some initial implantations in humans, the EC approved and financially supported the European Clinical Trial (ESPOIR), involving eight European pediatric centres and two TEs. The aim of this project was to achieve the 
implantation of cell-free pulmonary allograft valves in the RVOT of the pediatric patients with congenital valve malformations (ESPOIR Trial 2012). The shortterm performance of the valves used in this multicentric trial, has shown excellent results (Boethig et al. 2019).

Another multi-centric trial was carried out and finalized between 2015 and 2017 using cell-free aortic valves for the replacement of diseased aortic valves in children and young patients (ARISE Trial 2015). Again, cell-free aortic valves showed outstanding haemodynamic performance and a very low rate of complications during 5 years of $\mathrm{FU}$ (Horke et al. 2020). A Brazilian cardiac surgeon, da Costa reported the implantation of cell-free aortic valves using another decellularization protocol, showing similar promising early- to mid-term results (da Costa et al. 2010).

Our TE was the main supplier of pulmonary (ESPOIR) and aortic (ARISE) valve allografts for the patients included in these two European clinical trials (Boethig et al. 2019; Horke et al. 2020).

\section{Discussion and conclusion}

For over 30 years, our TE has been successfully selecting and processing human heart valves intended for human application. After cryopreservation and storage, securitization for transmissible diseases and quality controls, allograft valves are available for transplantation in patients with heart valve malformations (congenital/acquired). The results have been outstanding in adult patients, but moderate to poor in some other patient subgroups, such as neonates and infants (Dekens al. 2019; Hopkins 2006; Meyns et al. 2005). Although human heart valves represent the "gold standard" for the replacement of diseased/malformed heart valves, the ideal substitute is not yet available (Hopkins 2006). Despite their excellent haemodynamic performance, the accelerated structural failure of cryopreserved allograft valves in some patient subgroups has been reported in numerous studies (Dekens et al. 2019; Hopkins 2006; Meyns et al. 2005; Rajani et al. 1998). Accordingly, alternative solutions need to be envisaged with the implementation of new technologies, such as the engineering of human tissues or artificial scaffolds (Hopkins 2006).
Cardiovascular tissue banking in Europe represents a limited activity with approximately 20 active tissue establishments, compared to approximately 4000 other tissue establishments, involving conventional tissues, cells, blood and reproductive tissues (EDQM Newsletter 2018; Zahra et al. 2019a). Profound knowledge of cardiac morphology and pathology is required for persons taking care of the processing and release of the heart valve allografts with high quality and safety. Accordingly, the availability of a cardiac or vascular surgeon in the TE, represents added value for the TE, as he can resolve diverse medical and regulatory issues. Over the last 23 years, a cardiac surgeon supported our TE with availability $24 \mathrm{~h}$ a day. Consequently, the evaluation and judgement of some "borderline" valves was usually possible. Many of some "less perfect" tissues could be considered for alternative solutions in some particular situations (i.e., small pulmonary valves for paediatric patients), (Urso et al. 2012). The lack of a person with a cardiovascular background can also lead to the deferral of hearts with some "problems", such as a short pulmonary trunk, a cut in one leaflet and sinus, or the presence of a ventricular assist device in the heart of a living donors (for recipients of heart transplantation, RHT). In the past, a considerable number of valves from those hearts were accepted and used with outstanding results i.e., bicuspidized PVs, after meticulous evaluation in our TE (Jashari et al. 2013). A study performed by an international group of tissue banking experts, regarding the differences and similarities among TEs in Europe, reported important differences in volume and quality among the 19 participating establishments (Zahra et al. 2019a). Among the participants of this study, our TE was the only one with over 300 donated hearts (358 hearts in 2015), with two other "big" banks having recovered 200 and 150 hearts, respectively. All other European TEs recorded fewer than 100 donated hearts in 2015 . The high deferral rate might have also played an important role in the low donor numbers of some TEs. The majority of CVTEs in the EU are considered "multi-tissue banks".

Our TE is an authorized heart valve bank under Belgian legislation, but it has established an important international cooperation network, including Belgium, France, Germany, Luxemburg, the Netherlands, Switzerland, Italy and the UK. Despite some differences in the national regulations of the EUMS, there have been no considerable obstacles to cooperation in 
donation or transplantation. Due to this cooperation, the creation of a large pool of available allografts was possible. Thus far, we have been able to meet almost all demands for valves (for elective and emergency cases), with the exception of only a few cases with special demands (very small PVs or very large AVs). Furthermore, in some emergency cases, we were able to support other centres in "unusual" locations (Croatia, Denmark, Lithuania, New Zealand, Monaco, Saudi Arabia, Slovenia, Sweden, Turkey), although they were not supplying centres of hearts for our TE (Goffin et al. 2000; Jashari et al. 2013).

As in many TEs, a considerable number of demands (mainly) for pulmonary valves are received regularly, particularly for small (paediatric) sizes. This can be challenging for the responsible person of the TE, as these valves are not always available and searching for alternative solutions is also the duty of the TE. Enlarging the donor pool is a possibility, as PVs usually do not present atheromas or calcification (personal experience). The donor age has already been increased by some other centres, such as the German Heart Center in Berlin (Grosse et al. 2008). Based on this study and following our experience in the evaluation of human valves, extension of the donor age to 70 years was envisaged. For this purpose, a validation study was mandatory. Comparison of the (experimental) valves of donors up to 65 years of age (group 1) and those between 66 and 70 years of age (group 2) by means of mechanical testing, as well as light and electron microscopy, were carried out. The ultrastructure of valves (leaflets and conduit wall) was assessed. This study showed no differences between the groups (internal, unpublished data). Experimental valves were morphologically evaluated as well: there were no visible atheromas or sites of calcification in the conduit wall or leaflets of the valves in either group. According to the results of this study, we extended the donor age to 70 years (only for pulmonary valves). More than 100 pulmonary allograft valves in this age group have successfully been implanted (either as tricuspid valves, or after bicuspidization). To date, no problems have been reported with these valves by the implanting surgeons. The FU study is in progress.

The scarcity of valves is one of the concerns among cardiovascular TEs worldwide (Zahra et al. 2019a). The reason for this is the high discard rate due to a variety of factors, as mentioned in the Fig. 9 and
Table 1. Currently, our valve discard rate is between 50 and $70 \%$. The most important reason is morphologic alterations (mainly for donors of advanced age, Table 1). Furthermore, despite very important measures for the eradication of infection, it remains an important challenge for tissue bankers. In our TE, contamination is the second most common reason for valve discard with a rate of $17 \%$, (Fig. 9). All TEs have been confronted with this issue due to massive contamination during the recovery in the donation centres, insufficient decontamination with antibiotics (poor choice or combination of antibiotics), or inappropriate work in the laboratory of clinical biology (Zahra et al. 2019b). Accordingly, the European cardiovascular tissue banking working group has initiated a project for establishing an external quality assessment scheme for cardiovascular TE at the European level, with the aim of standardizing the tissue banking procedures and improving the clinical safety of tissue products. This project is in the developmental stage and our TE will be joining this group.

To evaluate the results of cryopreserved allograft valve transplantation, we have been working together with the implanting surgeons to assess the mid- to long-term performance of the valves. As a result a numerous FU studies have been performed and published (Dekens et al. 2019; Flameng et al., 2015; Hechadi et al. 2013; Kalangos et al. 2011; Meyns et al. 2005; Solari et al. 2016; Soquet et al. 2015). These studies have revealed important information on the long-term performance and behaviour of cryopreserved allograft valves. On the other hand, some of these studies had as an objective the assessment of patients receiving allografts for life-threatening situations with a high mortality risk immediately after surgery, such as endocarditis with annular abscesses and septic conditions (Flameng et al. 2015; Solari et al. 2016). These patients usually underwent emergency surgery. Although the cryopreserved allograft valves used in those cases showed very high resistance to infection, important SVF appeared as soon as 10 years of implantation.

A study regarding the durability of pulmonary allograft used for the replacement of diseased pulmonary valves showed significantly better outcomes in adult patients than in neonates and children up to 10 years of age. In this patient subgroup, allograft replacement was mandatory in approximately $60 \%$ of 
cases within only 5 years after implantation (Meyns et al. 2005). Another study indicated the immune aspect as an important factor of the accelerated structural failure of transplanted valves, as significantly better outcomes were observed in cases with than without ABO matching (Dekens et al. 2019). Likewise, some other studies have shown that the immune issues of implanted allografts, currently considered the main factor of their accelerated deterioration, might be solved by removing all living elements from allografts (living cells), creating nonimmunogenic valves (cell-free natural scaffolds). The implantation of such acellular scaffolds in neonates, children and young patients might result in natural reseeding with cells of the recipient. Indeed, this supposition has been confirmed in some animal studies (Baraki et al. 2009; Cebotari et al. 2011; Hopkins 2006; Tudorache et al. 2016). Eliminating multiple reoperations for neonates and children will reduce their mortality and suffering (Hopkins 2006).

Following the preliminary works of the group from the Hannover Medical School and approval of these valves for transplantation by the German Competent Authority, two multi-centric studies ("ESPOIR" and “ARISE") were carried out including 200 and 120 patients, respectively, with pulmonary or aortic valve malformations. The valves were decellularized by "Corlife", a part of the Hanover Medical School. Our TE was the main supplier of the allograft valves for both studies, delivering more than 100 pulmonary valves and 180 aortic valves during and after these two studies. Cell-free valves have been implanted in Austria, Belgium, France, Germany, the Netherlands, Italy, Moldavia, Spain, Switzerland and United Kingdom. The preliminary results of these two multicentric trials showed superior results of cell-free allografts compared to cryopreserved valves. Accordingly, several papers have reported promising results during the last 5 years (Boethig et al. 2019; Horke et al. 2020; Tudorache et al. 2007; Sarikouch et al. 2019), including the youngest patient subgroup (Horke et al. 2020).

In the coming years, TEs as well as members of the surgical community are expecting answers to the questions of whether cell-free allografts are recellularized after implantation in the patient and whether they can follow the growth of very young, fastgrowing patients. At present, these are only suppositions (Hopkins 2006; Sarikouch et al. 2019).
Due to the extensive high price currently, cell-free allograft valves are authorized (and reimbursed), only in Germany, Austria and Switzerland. Consequently, not every patient who needs such a valve is able to receive it. Hence, non-profit TEs in Europe should invest in obtaining technology and knowhow for establishing tissue engineered heart valve programs with the aim of offering these valves to as many patients as possible for a reasonable price and/or full reimbursement by healthcare insurance.

In conclusion, serious improvement has occurred over the last 3 decades in the selection, preparation, storage and distribution of quality-controlled cryopreserved allograft valves, making them available for the surgical community and ensuring safety and security for patients. Our TE has been one of the key players in the domain. Although cryopreserved valves represent best available solution for the treatment of diseased valves, clear evidence of accelerated allograft valve failure has been demonstrated in some patient subgroups. The implementation of new technologies, such as decellularization, as a standard procedure for treatment with allograft valves might offer further improvements in allograft quality and increase in durability.

Acknowledgements I would like to thank Mme. Beatrice Van Hock very much for her availability and contribution to all activities presented in this paper.

Funding There was no funding required for this paper.

\section{Compliance wih ethical standards}

Conflict of interest There is no conflict of interest with this paper. Dr. Jashari is a Director of the EHB.

Ethics approval The EHB is a non-profit TE and it holds an ethical approval for its activity (donation, transplantation, research). All donors reported in this study have given their consent for organ/tissue donation for clinical application and/or research in compliance with the EU/Belgian tissue banking regulation.

\section{References}

ARISE (Home). www.arise-clinicaltrial.eu

Baraki H, Tudorache I, Braun M et al (2009) Orthotopic replacement of the aortic valve with decellularized allograft in a sheep model. Biomaterials 30(31):6240-6246. https://doi.org/10.1016/j.biomaterials.2009.07.068 
Barratt-Boyes BG (1964) Homograft aortic valve replacement in aortic valve incompetence and stenosis. Thorax 19:131-150

Baskett RJF, Nanton MA, Warren AE, Ross DB (2003) Human leukocyte antigen-DR and $\mathrm{ABO}$ mismatch are associated with accelerated homograft valve failure in children: implications for therapeutic interventions. J Thorac Cardiovasc Surg 126(1):233-238

Boethig D, Horke A, Hazekamp MA et al (2019) European study on decellularized homografts for pulmonary valve replacement: initial results from the prospective ESPOIR Trial and ESPOIR Registry data $\uparrow$. Eur J Cardiothorac Surg. 56(3):503-509. https://doi.org/10.1093/ejcts/ezz054

Burkert J, Kochová P, Tonar Z et al (2020) The time has come to extend the expiration limit of cryopreserved allograft heart valves. Cell Tissue Bank. https://doi.org/10.1007/s10561020-09843 (PMID: 32583302)

Cebotari S, Tudorache I, Ciubotaru A et al (2011) Use of fresh decellularized allografts for pulmonary valve replacement may reduce the reoperation rate in children and young adults: early report. Circulation 124(11):S115-S123. https://doi.org/10.1161/CIRCULATIONAHA.110.012161

Cebotari S, Tudorache I, Jaekel T et al (2010) Detergent decellularization of heart valves for tissue engineering: toxicological effects of residual detergents on human endothelial cells. Artif Organs 34(3):206-210. https://doi. org/10.1111/j.1525-1594.2009.00796.x

Commission directive 2006/17/EC of 8 February 2006 implementing Directive 2004/23/EC of the European Parliament and of the Council as regards certain technical requirements for the donation, procurement and testing of human tissues and cells. https://eur-lex.europa.eu/legal-content/ EN/TXT/?uri=celex\%3A32004L0023

Commission directive 2006/86/EC of 24 October 2006 implementing Directive 2004/23/EC of the European Parliament and of the Council as regards traceability requirements, notification of serious adverse reactions and events and certain technical requirements for the coding, processing, preservation, storage and distribution of human tissues and cells. https://eur-lex.europa.eu/legal-content/EN/TXT/ ?uri=celex\%3A32004L0023

da Costa F, Costa AC, Prestes R et al (2010) The early and midterm function of decellularized aortic valve allografts. Ann Thorac Surg 90(6):1854-1860. https://doi.org/10. 1016/j.athoracsur.2010.08.022

Dekens E, Van Damme E, Jashari R, Van Hoeck B, François K, Bové T (2019) Durability of pulmonary homografts for reconstruction of the right ventricular outflow tract: how relevant are donor-related factors? Interact Cardiovasc Thorac Surg 28(4):503-509. https://doi.org/10.1093/icvts/ ivy 316

Díaz Rodríguez R, Van Hoeck B, De Gelas S et al (2017) Determination of residual dimethylsulfoxide in cryopreserved cardiovascular allografts. Cell Tissue Bank. 18(2):263-270. https://doi.org/10.1007/s10561-016-96070

Díaz Rodríguez R, Van Hoeck B, Mujaj B et al (2016) Bacteriology testing of cardiovascular tissues: comparison of transport solution versus tissue testing. Cell Tissue Bank 17(2):211-218. https://doi.org/10.1007/s10561-015-95372
Directive 2004/23/EC of the European Parliament and of the Council of 31 March 2004 on setting standards of quality and safety for the donation, procurement, testing, processing, preservation, storage and distribution of human tissues and cells. https://eur-lex.europa.eu/legal-content/ EN/TXT/?uri=celex\%3A32004L0023

EDQM (2018) Organs, tissues, blood and cells for transplantation in the European Union, vol 23. EDQM, Newsletter

EDQM (2019) Guide to the quality and safety of tissues and cells for human application, 4th edn. www.edqm.eu

E-GTP. http://goodtissuepractices.eu/images/outcomes/ EuroGTP_Final_Delivery.pdf

ESPOIR (Home). www.espoir-clinicaltrial.eu

Fan YD, Van Hoeck B, Holovska V, Jashari R (2012) Evaluation of decontamination process of heart valve and artery tissues in European Homograft Bank (EHB): a retrospective study of 1,055 cases. Cell Tissue Bank 13(2):297-304. https://doi.org/10.1007/s10561-011-9255-3 (Epub 2011 Apr 23)

Flameng W, Daenen W, Jashari R, Herijgers P, Meuris B (2015) Durability of homografts used to treat complex aortic valve endocarditis. Ann Thorac Surg. 99(4):1234-1238. https:// doi.org/10.1016/j.athoracsur.2014.11.002

Gibbon JH (1954) Application of a mechanical heart and lung apparatus to cardiac surgery. Minn Med 37:171-174

Goffin YA, Van Hoeck B, Jashari R et al (2000) Banking of cryopreserved heart valves in Europe: assessment of a 10-year operation in the European Homograft Bank (EHB). J Heart Valve Dis 9(2):207-214

Grossee K, Meyer R, Schmitzer E et al (2008) Are heart valves from donors over 65 years of age morphologically suitable for transplantation. Cell Tissue Banking 9:31-36. https://doi.org/10.1007/s10561-007-9052-1

Hechadi J, Gerber BL, Coche E et al (2013) Stentless xenografts as an alternative to pulmonary homografts in the Ross operation. Eur J Cardiothorac Surg 44(1):e32-e39. https:// doi.org/10.1093/ejcts/ezt147 (Epub 2013 Mar 18)

Hopkins R (2006) From cadaver harvested homograft valves to tissue-engineered valve conduits. Progress in Pediatric Cardiology 21:137-152

Horke A, Bobylev D, Avsar M, Sarikouch S et al (2020) Paediatric aortic valve replacement using decellularized allografts. Eur J Cardiothorac Surg. 58(4):817-824. https://doi. org/10.1093/ejcts/ezaa119

Jashari R, Van Hoeck B, Tabaku M, Vansderkelen A (2004) Banking of the human heart valves and the arteries at the European Homograft Bank (EHB). Overview of a 14 years activity in this International Association in Brusses. Cell Tissue Bank 5:239-251

Jashari R, Tabaku M, Van Hoeck B et al (2007) Decontamination of heart valve and arterial allografts in the European Homograft Bank (EHB): comparison of two different antibiotic cocktails in low temperature conditions. Cell Tissue Bank 8(4):247-255. https://doi.org/10.1007/ s10561-007-9040-5 (Epub 2007 Apr 13)

Jashari R, Goffin Y, Van Hoeck B et al (2010) European homograft bank: twenty years of cardiovascular tissue banking and collaboration with transplant coordination in Europe. Transplant Proc 42(1):183-189. https://doi.org/10. 1016/j.transproceed.2009.11.022 
Jashari R, Faucon F, Hoeck BV et al (2011) Determination of residual antibiotics in cryopreserved heart valve allografts. Transfus Med Hemother 38(6):379-386. https://doi.org/ $10.1159 / 000334706$

Jashari R, Van Hoeck B, Ngakam, et al (2013) Banking of cryopreserved arterial allografts in Europe: 20 years of operation in the European Homograft Bank (EHB) in Brussels. Cell Tissue Bank 14(4):589-599. https://doi.org/ 10.1007/s10561-012-9359-4

Jashari R, Vanzeebroeck S, Petit P, et al (2020) The BD BACTEC FX blood culture system with the gentle MACS dissociator is suitable for sterility testing of heart valve and vascular allografts. A validation study. cell tissue bank. doi: https://doi.org/10.1007/s10561-020-09893-6.

Kalangos A, Cikirikcioglu M, Cherian S, Stimec B, Jashari R, Fasel J (2011) Mitral valve replacement using a mitral homograft. Multimed Man Cardiothorac Surg. 1(916):mmcts.2010.004903. https://doi.org/10.1510/ mmcts.2010.004903

Klykens J, Pirnay JP, Verbeken G et al (2013) Cleanrooms and tissue banking how happy I could be with either GMP or GTP? Cell Tissue Bank 14(4):571-578. https://doi.org/10. 1007/s10561-012-9355-8 (Epub 2013 Jan 4)

Meyns B, Jashari R, Gewillig M et al (2005) Factors influencing the survival of cryopreserved homografts. The second homograft performs as well as the first. Eur J Cardiothorac Surg. 28(2):211-216. https://doi.org/10.1016/j.ejcts.2005. 03.041

Murray G (1956) Homograft aortic valve segment transplant as surgical treatment for aortic and mitral insufficiency. Angiology 7:466

O'Brien MF, Stafford G, Gardner M et al (1987) The viable cryopreserved allograft aortic valve. J Card Surg 2(1 Suppl):153-167. https://doi.org/10.1111/jocs.1987.2.1s. 153

Rajani B, Roger BS, Mee MB et al (1998) (1998) Evidence for rejection of homograft cardiac valves in infants. Thorac Cardiovasc Surg 115:111-117

Ross DN (1962) Homograft Replacement of aortic valve. Lancet II:487

Rubay JE, Buxcxhe M, El Khoury GA, at all, (1999) The Ross operation: mid-term results. Ann Thorac Surg 67:1355-1358

Solari S, Mastrobuoni S, De Kerchove L et al (2016) Over 20 years experience with aortic homograft in aortic valve replacement during acute infective endocarditis. Eur $\mathbf{J}$ Cardiothorac Surg 50(6):1158-1164. https://doi.org/10. 1093/ejcts/ezw175 (Epub 2016 May 26)
Soquet J, Chambon JP, Goffin Y, Jashari R (2015) Acute rejection of a cryopreserved arterial homograft. Cell Tissue Bank 16(3):331-333. https://doi.org/10.1007/s10561-0149489-y (Epub 2014 Dec 16)

Sarikouch S, Theodoridis K, Hilfiker A et al (2019) Early insight into in vivo recellularization of cell-free allogenic heart valves. Ann Thorac Surg 108(2):581-589. https://doi.org/ 10.1016/j.athoracsur.2019.02.058

Tabaku M, Jashari R, Carton HF et al (2004) Processing of cardiovascular allografts: effectiveness of European Homograft Bank (EHB) antimicrobial treatment (cool decontamination protocol with low concentration of antibiotics). Cell Tissue Bank. 5(4):261-266. https://doi. org/10.1007/s10561-004-1440-1

Tudorache I, Theodoridis K, Baraki H et al (2016) Decellularized aortic allografts versus pulmonary autografts for aortic valve replacement in the growing sheep model: haemodynamic and morphological results at 20 months after implantation. Eur J Cardiothorac Surg. 49(4):1228-1238. https://doi.org/10.1093/ejcts/ezv362 (Epub 2015 Oct 24)

Tudorache I, Cebotari S, Sturz G et al (2007) Tissue engineering of heart valves: biomechanical and morphological properties of decellularized heart valves. J Heart Valve Dis. 16(5):567-573

Urso S, Rega F, Gewillig M et al (2012) Evolution of the Z-score in size-reduced bicuspid homografts". J Heart Valve Dis 4:521-526

Wassenaar C, Wijsmuller EG, Van Herwerden LA et al (1995) Cracks in cryopreserved aortic allografts and rapid thawing. The Ann Thorac Surg 60:S165-S167.

Willis BH, Quigley M (2014) Opt-out organ donation: on evidence and public policy. J Royal Soc Med 107(2):56-60. https://doi.org/10.1177/0141076813507707

Zahra S Galea G, Jashari R, Petit P, de By TMMH, (2019a) Significant variation in heart valve banking Practice. Eur J Clin Microbiol Infect Dis 38:1491-1498. https://doi.org/ 10.1007/s10096-019-03577-0

Zahra S, Galea G, Jashari R, Petit P, de By TMMH, (2019b) Validation of microbiological testing in cardiovascular tissue establishments: results of a second international quality-round trial. Eur $\mathrm{J}$ Clin Microbiol Infect Dis 38:1481-1490. https://doi.org/10.1007/s10096-01903576-1

Publisher's Note Springer Nature remains neutral with regard to jurisdictional claims in published maps and institutional affiliations. 